\title{
JARINGAN KOMUNIKASI PENDUDUK LOKAL DI DESA WISATA PETINGSARI, KABUPATEN SLEMAN, YOGYAKARTA
}

\author{
Retno Dyah Kusumastuti, Antar Venus \\ Universitas Pembangunan Nasional "Veteran" Jakarta \\ rdnino@gmail.com
}

\begin{abstract}
ABSTRAK
Pada tahun 1990-an Desa Pentingsari mendapat predikat Desa Wisata dengan pendapatan yang relative rendah. Padahal potensi desa cukup besar dengan luas 105 hektar dengan komposisi lahan pekarangan, perkebunan, sawah, lading dan daerah aliran sungai, kendalanya kondisi desa cukup terpencil karena belum baiknya akses. Masyarakat bertekad keluar dari kondisi kemiskinan itu, alam dan lingkungan dirawat, sehingga hasil bumi dari kekayaan alam meningkat. Pendekatan Desa Wisata dipilih oleh penduduk karena merasa pariwisata bisa menjadi cara untuk melibatkan seluruh komponen masyarakat. Penelitian ini ingin mengetahui jaringan komunikasi penduduk local di Desa Wisata Pentingsari yang telah berhasil keluar dari kondisi kemiskinan dengan mengubah desanya menjadi desa wisata yang berhasil.

Kata kunci: Penduduk lokal, Jaringan Komunikasi Desa Wisata Pentingsari.
\end{abstract}

\section{Pendahuluan}

Modernisasi merupakan proses perubahan individual dari gaya hidup tradisional ke suatu cara hidup yang lebih kompleks, secara teknologis lebih maju dan berubah cepat. Perubahan dari tradisional menjadi modern memerlukan komunikasi, agar ide-ide baru itu dapat diterima oleh suatu komunitas masyarakat atau suatu institusi. Oleh karena itu komunkasi menjadi faktor penting dalam implementasi dan terlaksananya perubahan tersebut (Rogers dan Svenning, $1969: 48$ )

Proses masuknya ide-ide baru dalam tatanan sosial masyarakat tersebut sebenarnya merupakan proses komunikasi. Mula-mula gagasan/ide baru dikomunikasikan baik langsung maupun tidak langsung dengan berbagai cara. Proses komunikasi ini semakin lama semakin mendalam sehingga masyarakat dapat memahami pada berbagai tingkatan. Mungkin saja ada yang langsung menolak, ada yang menerima namun lambat, dan ada yang menerima dengan cepat

Tujuan dari pemasukan ide-ide baru (inovasi) ke dalam masyarakat melalui proses komunikasi ini adalah untuk melakukan perubahan-perubahan pada masyarakat. 
Kegiatan ini tidak hanya untuk negara-negara berkembang saja, tetapi juga dinegara maju. Gagasan baru diharapkan memperbaiki pengetahuan, perilaku/ sikap dalam masyarakat sehingga terjadi perubahan dalam masyarakat sesuai tujuan pemasukan ideide baru itu tercapai karena pada dasarnya perubahan social diperlukan untuk memperbaiki kondisi masyarakat kearah yang lebih baik.

Dalam upaya memasukkan gagasan baru (inovasi) ke dalam suatu tatanan masyarakat perlu mencermati beberapa hal karena masyarakat bukanlah benda mati, misalnya kebaruan dari gagasan tersebut. Semakin baru gagasan tersebut semakin besar kemungkinan suatu gagasan tersebut diterima. Selain itu juga kegunaan dari gagasan tersebut. Semakin tinggi tingkat kegunaannya untuk memecahkan persoalan yang ada maka tingkat penerimaannya semakin tinggi pula.

Salah satu gagasan baru (inovasi) untuk memecahan persoalan yang ada di masyarakat khususnya desa adalah Desa wisata. Desa wisata merupakan desa yang membuka diri untuk menerima kunjungan wisata lebih dari sekedar obyek atau daya tarik wisata. Dalam hal Desa wisata, termasuk di dalamnya ketersediaan akomodasi dan fasilitas lainnya sehingga wisatawan tidak saja berkunjung, namun juga menetap di desa tersebut.

Desa wisata merupakan desa yang membuka diri untuk menerima kunjungan wisata lebih dari sekadar objek atau daya tarik wisata. Dalam hal desa wisata, termasuk di dalamnya ketersediaan akomodasi dan fasilitas lainnya sehingga wisatawan tidak saja datang berkunjung dan kembali, tetapi menetap di desa wisata. Pengertian Desa wisata berbeda dengan "Wisata Desa" yang mengacu pada aktivitas wisatawan yang berkunjung ke perdesaan tanpa tujuan untuk bermalam di tempat tersebut karena tidak tersedia fasilitas untuk itu. Dalam aktivitas tour ke desa ini, desa hanya sebagai objek atau daya tarik wisata. 
Pentingsari merupakan salah satu desa wisata yang berada di daerah Yogyakarta, Kabupaten Sleman, Desa Umbulharjo, Kecamatan Cangkringan tepatnya berjarak sekitar $12 \mathrm{~km}$ dari puncak Gunung Merapi. Desa ini memiliki hawa sejuk dan menyegarkan. Pada tahun 1990-an Pentingsari mendapat predikat Desa miskin dengan pendapatan masyarakat yang relatif rendah. Padahal, potensi desa cukup besar dengan luas 103 hektare dengan komposisi lahan pekarangan, perkebunan, sawah, ladang, dan daerah aliran sungai. Kendalanya, kondisi desa cukup terpencil karena belum baiknya akses.

Masyarakat bertekad keluar dari kondisi kemiskinan itu. Alam dan lingkungan dirawat sehingga hasil bumi dan kekayaan alam meningkat. Pada tahun 2008, Sumardi, tetua sekaligus perintis Desa wisata Pentingsari bersama warga Pentingsari memberanikan diri menjadi tuan rumah bagi masyarakat luar dengan membuka desanya sebagai desa wisata. Hal ini diharapkan menjadi cara untuk meningkatkan taraf ekonomi sekaligus membangun kesadaran untuk merawat desa.

Pendekatan inovasi desa wisata ini dipilih karena pariwisata bisa menjadi cara untuk melibatkan seluruh komponen masyarakat. Ada yang menyediakan homestay, memasak; menjadi guide; menjadi pelatih outbond; memberi pelatihan tari, karawitan atau membuat wayang suket. Menurut penduduk setempat, setiap tahun kunjungan ke desa wisata ini selalu meningkat, baik dari anak sekolahan, karyawan perusahaan, anak kuliahan, turis asing dan para pensiunan yang memang sengaja datang hanya ingin berwisata atau belajar kebudayaan di sana.

Desa wisata Pentingsari memiliki 3 aspek yang membuat selalu ramai dikunjungi. Pertama, adalah keunikan alam yang terjaga. Di sini, wisatawan dapat melihat hamparan sawah yang luas membentang. Kedua, sistem kerja dan perberdayaan masyarakat sekitar, di mana semua tenaga kerja dan pengelola Desa wisata Pentingsari yakni penduduk lokal. Dan yang ketiga adalah budaya, lereng merapi pada umumnya masih memegang teguh 
budaya jawa, dimana homestay yang ada di desa tersebut kebanyakan berbentuk rumah khas Jogja (https://eksotisjogja.com/desa-wisata-pentingsari-kabupaten-slemanyogyakarta/).

Pemberdayaan penduduk lokal yang menjadi salah satu penggerak desa wisata Pentingsari serta gagasan untuk menyebarkan motivasi berprestasi dalam penerapan teknologi wisata desa itu memerlukan tata cara khusus, karena mengajak petani untuk berubah itu tidak mudah dalam mnyebarkan gagasan membuat peneliti ingin mengetahui lebih jelas peran jaringan komunikasi dalam pengembangan wisata desa.

Pengembangan Desa wisata disebarkan melalui Jaringan komunikasi Proses pertukaran informasi yang terjadi antar penduduk dalam mencari dan menyebarkan informasi obyek wisata dapat dilakukan dengan metode analisis jaringan komunikasi. Jaringan komunikasi penting untuk dipelajari karena dapat menggambarkan jaringan kepada siapa mereka bertanya dan oleh siapa saja mereka ditanya.

Proses pertukaran informasi yang terjadi dari dua orang atau lebih menggambarkan adanya jaringan yang muncul sebagai akibat kebutuhan informasi. Proses pertukaran informasi yang terjadi bisa lewat tatap muka secara langsung atau melalui media komunikasi. Indvidu yang berinteraksi memiliki peran dalam sebuah jaringan tergantung kepada intensitas mereka dalam menerima atau memberikan informasi.

Menurut Rogers dan Kincaid (1981), tujuan penelitian jaringan komunikasi adalah untuk memahami fenomena secara umum mengenai interaksi manusia dalam sistem sosial dan mengidentifikasi struktur komunikasi yang menyusunnya. Peran masing-masing aktor dalam jaringan komunikasi berbeda-beda, konsep pemuka pendapat (opinion leader) dan penjaga gerbang (gatekeeper) dikenal dalam mempercepat penyebaran suatu gagasan atau teknologi baru kepada masyarakat. Dalam sebuah 
jaringan komunikasi terdiri atas beberapa elemen penting diantaranya yaitu : (1) aktor (node) tidak selalu berupa individu, bisa juga organisasi, negara, institusi dan sebagainya.(Scoot, Baggio and Cooper, 2008 : 146), (2) relasi antar aktor yang dlambangkan dalam suatu garis yang menghubungkan antar aktor, (3) komponen adalah pengelompokan aktor yang sekurangnya mempunyai satu link dalam jaringan , (4) klik adalah pengelompoan aktor yang ditandai dengan adanya relasi antar aktor secara lengkap dan maksimal, (5) brigdes adalah jembatan yang meenghubungkan dua kelompok terpisah dalam suatu jaringan, (6) Hubs adalah aktor (node) yang mempunyai koneksi paling banyak dalam jaringan ( Golbeck, 2013 : 21 ).(7) Cutpoints adalah aktor yang menjadi perekat dari jaringan, bila tidak ada aktor tersebut maka jaringan akan terpecah ( Borgatti and Delody, 2013 ), (8) pemencil atau isolate adalak aktor (node) yang tidak mempunyai satu pun link dengan aktor lain dalam jaringan.

Jaringan Komunikasi yang terbentuk dari aktivitas penduduk Desa Pentingsari dalam berkomunikasi dilihat sebagai upaya penduduk desa dalam mendapatkan informasi inovasi Desa wisata dengan cara mencari, menerima dan menyebarkan kembali, dan pada akhirnya menerapkan inovasi desa wisata yang dapat mendukung peningkatan kwalitas desa wisata. Semakin tinggi aktivitas individu penduduk desa dalam berhubungan dengan individu lain mengindikasikan semakin banyak informasi desa wisata yang dipertukarkan maka semakin tinggi pula penerapa inovasi desa wisata.

Adapun tujuan penelitian adalah: (1) mendeskripsikan struktur jaringan komunikasi dan peran aktor dalam mencari infomasi, (2) mendeskripsikan karakteristik individu dan karakteristik usaha desa wisata yang mendasari terbentuknya struktur jaringan komunikasi penduduk, (3) menganalisis hubungan antara jaringan komunikasi dengan penerapan inovasi desa wisata di Desa Pentingsari.Kecamatan Cangkringan Kabupaten Sleman. 


\section{Tinjauan Pustaka}

Pertimbangan memilih pendekatan dengan teori jaringan komunikasi, adalah jaringan komunikasi dipakai untuk mengkaji kelompok penduduk lokal desa wisata Pentingsari, di desa Umbulharjo Kecamatan Cangkringan. Sedangkan teori modernisasi yang di dalamnya terdapat variabel motivasi berprestasi dipakai untuk menganalisa sejauh mana kelompok penduduk lokal dalam memotivasi dirinya untuk mencapai kehidupan yang lebih baik. Sedangkan teori konvergensi simbolik yang merupakan teori yang mengetengahkan analisa-analisa tema fantasi dipakai sebagai upaya menjelaskan tentang motivasi berprestasi.

Penelitian yang mempergunakan variabel motivasi berprestasi sebagai kondisi awal yang mampu mempengaruhi tingkat keberhasilan modernisasi belum banyak dilakukan. Kalaupun ada, di tahun sebelum 1960 an, misalnya penelitian McClleland. Oleh karena itu penelitian ini dilakukan karena ada beberapa pertimbangan yang antara lain, masih sedikitnya upaya mengkaji motivasi berprestasi sebagai kondisi awal yang mampu mempengaruhi tingkat keberhasilan modernisasi.

Berikut ini dipaparkan teori-teori yang relevan dengan permasalahan penelitian dan kerangka pemikiran menjadi dasar melakukan penelitian. Terlebih dahulu akan dipaparkan mengenai analisis kelompok kecil dan komunikasi dalam kelompok kecil, state of the art studi motivasi berprestasi, perkembangan studi modernisasi, jaringan komunikasi, proses komunikasi pada jaringan komunikasi, model komunikasi konvergensi, karakteristik individu, peran opinion leader, teori konvergensi simbolik, elemen-elemen konvergensi simbolik, dan kerangka pemikiran teoritis.

\section{Metodologi}

Desain Penelitian 
Penelitan Jaringan komunikasi ini menggunakan pendekatan kuantitatif yang bersifat deskriptif dan korelasional. Pemilihan pendekatan kuantitatif ini dimaksudkan untuk menggambarkan secara detail fenomena sosial yang dilihat dari sudut pandang peneliti dan penduduk sebagai obyek penelitian. Pendekatan penelitian ini ingin menggambarkan bagaimana secara detail jaringan komunikasi yang terdiri dari struktur jaringan, siapa saja aktor-aktor yang di dalamnya dan bagaimana posisi aktor-aktor dalam jarngan. Selain itu pendekatan kuatitatif dipilih peneliti untuk menjelaskan hubungan antar peubah yang digunakan dalam penelitian melalui proses penghitungan data yang dikuantifikasi, sehingga dapat melihat korelasi atau hubungan antarvariable.

Jaringan komunikasi dalam penelitian ini ditelaah berdasarkan informasi Desa wisata yang obyek - obyeknya terdiri dari (1) wisata Pancuran suci Sendangsari, (2) wisata Luweng, (3) wisata rumah Joglo (4) wisata alam (5) Batu Dakon (6) wisata Ponteng, (7) wisata jalur tracking. Fokus penelitian adalah untuk mendeskripsikan variabel jaringan komunikasi yang ditekankan pada Analisa jaringan utuh (complete networks). Jaringan komunikasi yang dipilih sebagai indikator adalah sentralitas tingkatan, sentralitas kedekatan, sentralitas kesetaraan .

Penentuan Lokasi dan Waktu Peneliian

Penelitian ini dilakukan pada penduduk desa Pentingsari, Kecamatan Cangkringan, Kabupaten Sleman. Penelitian ini dilakukan mulai bulan juni sampai dengan juli 2018.

Populasi dan Sampel

Penentuan populasi menggunakan pendekatan nominalis dan batasan waktu (event based) yaitu menentukan definisi jaringan komunikasi dan batasan-batasan anggota didasarkan oleh keikutsertaan atau keterlibatan aktor pada peristiwa tertentu sehingga populasi adalah penduduk desa wisata Pentingsari, Kecamatan Cangkringan 
Kabupaten Sleman yang menjalankan usaha desa wisata Pentingsari.Tehnik pengambilan sampel dilakukan dengan menggunakan sampel kelompok kecil yaitu mengambil satu kelompok dan mengambil semua anggota anggota dari kelompo tersebut (Eriyanto, 2014).

Metode pengumpuan data yang dikumpulkan adalah data primer dan data sekunder, melalui wawancara pada aktor jaringan dan melalui studi literatur, buku-buku, catatan-catatan atau laporan-laporan proses pengumpulan data dilakukan secara bertahap yaitu dengan melakukan pengamatan dan observasi, selanjutnya pengumpulan data primer langsung kepada aktor.

\section{Hasil Penelitian/Analisis}

Dalam penelitian ini Teknik analisis data yang digunakan adalah:

Analisis Jaringan komunikasi, analisis jarngan lebih menekankan pada jaringan utuh (complete networks) yaitu level aktor, level system dan level kelompok. Analisis jaringan komunikasi dilakukan dengan pendekatan deskriptif. Data yang diambil adalah data relasional antara satu aktor dengan aktor lain kemudian dimasukkan dalam matriks hubungan. Data diolah menggunakan soft UCINET VI. Untuk melihat struktur jaringan komunikasi.

Hasil penelitian mengenai jaringan komunikasi penduduk local di Desa Pentingsari ini menggambarkan struktur komunikasi yang terjalin antar responden dalam bentuk sosiogram. Melaluisosiogram tersebut, dapat diketahui dengan siapa dan kepada siapa responden sering berkomunikasi, siapa yang paling banyak menjadi partner komunikasi dan siapa yang paling sedikit menjadi partner komunikasi. 


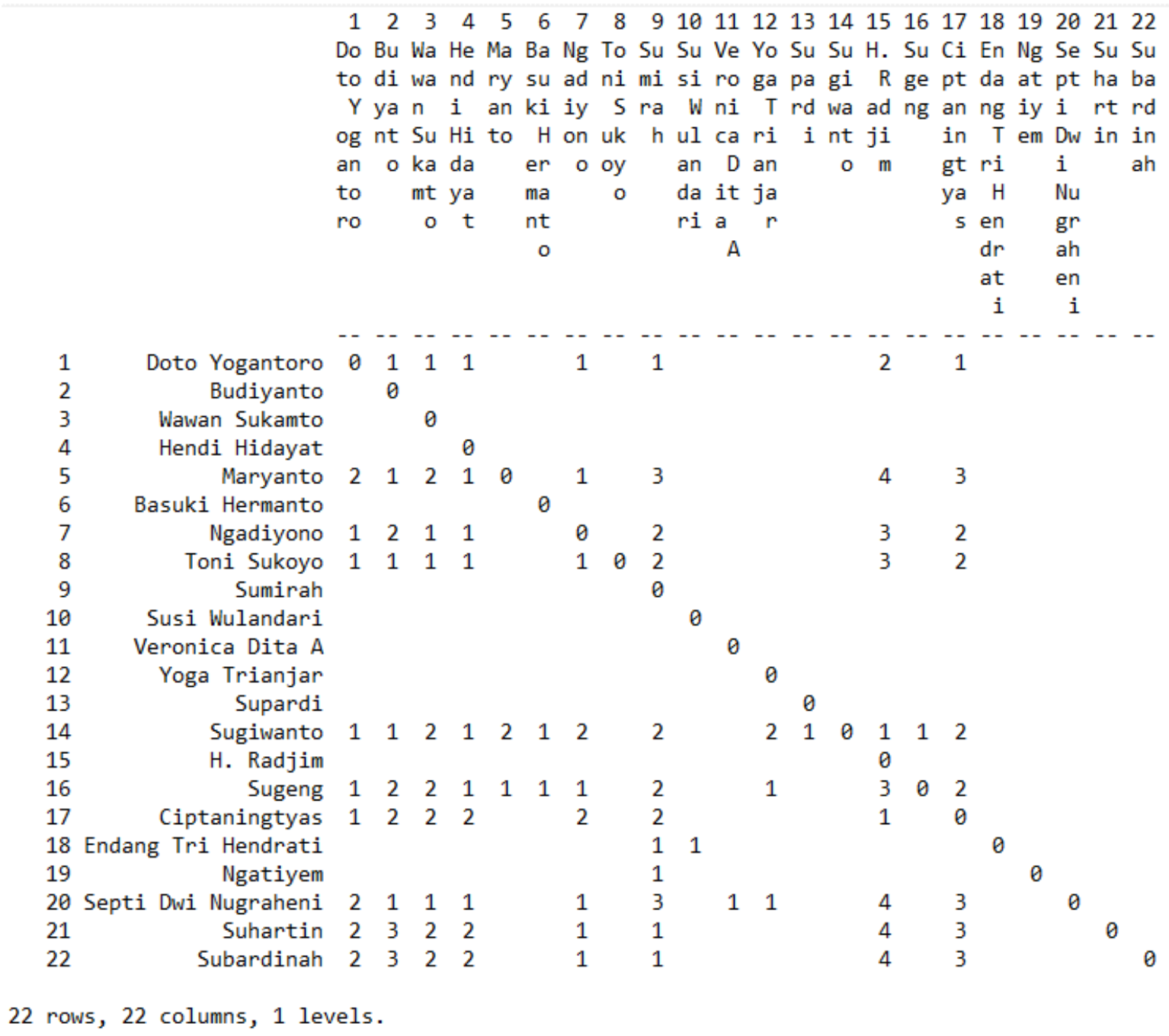

Gambaran tentang proses tersebut disajikan dalam bentuk data sosiometri pada Tabel 1 Tabel 1. Data who to whom matrix

Dari data sosiometri yang disajikan pada tabel, dapat dilihat individu-individu mana yang paling banyak berkomunikasi, individu yang paling sedikit berkomunikasi. Dari tabel terlihat bahwa individu yang paling banyak menerima jumlah pilihan partner berkomunikasi adalah Doto Yogantoro, Ngadiyono, dan Hendi Hidayat dan yang lainnya merupakan individu yang tidak mendapat pilhian sebagai partner berkomunikasi.

Di samping itu dapat dikatakan struktur jaringan komunikasi yang terjadi dalam kelompok usaha desa wisata masuk dalam struktur semua saluran dalam arti semua 
anggota adalah sama dan semuanya juga memiliki kekuatan yang sama untuk mempengaruhi anggota lainnya. Akan tetapi dalam struktur semua saluran, setiap anggota bisa berkomunikasi dengan setiap anggota lainnya, Pola ini memungkinkan adanya partisipasi anggota secara optimum. Meskipun tidak semua anggota kelompok membentuk struktur semua saluran, namun bisa dikatakan ada sekitar $70 \%$ anggota kelompok yang bisa dikategorikan dalam struktur tersebut. Dengan demikian bisa dikatakan komunikasi antara anggota kelompok berlangsung dalam kesetaraan.

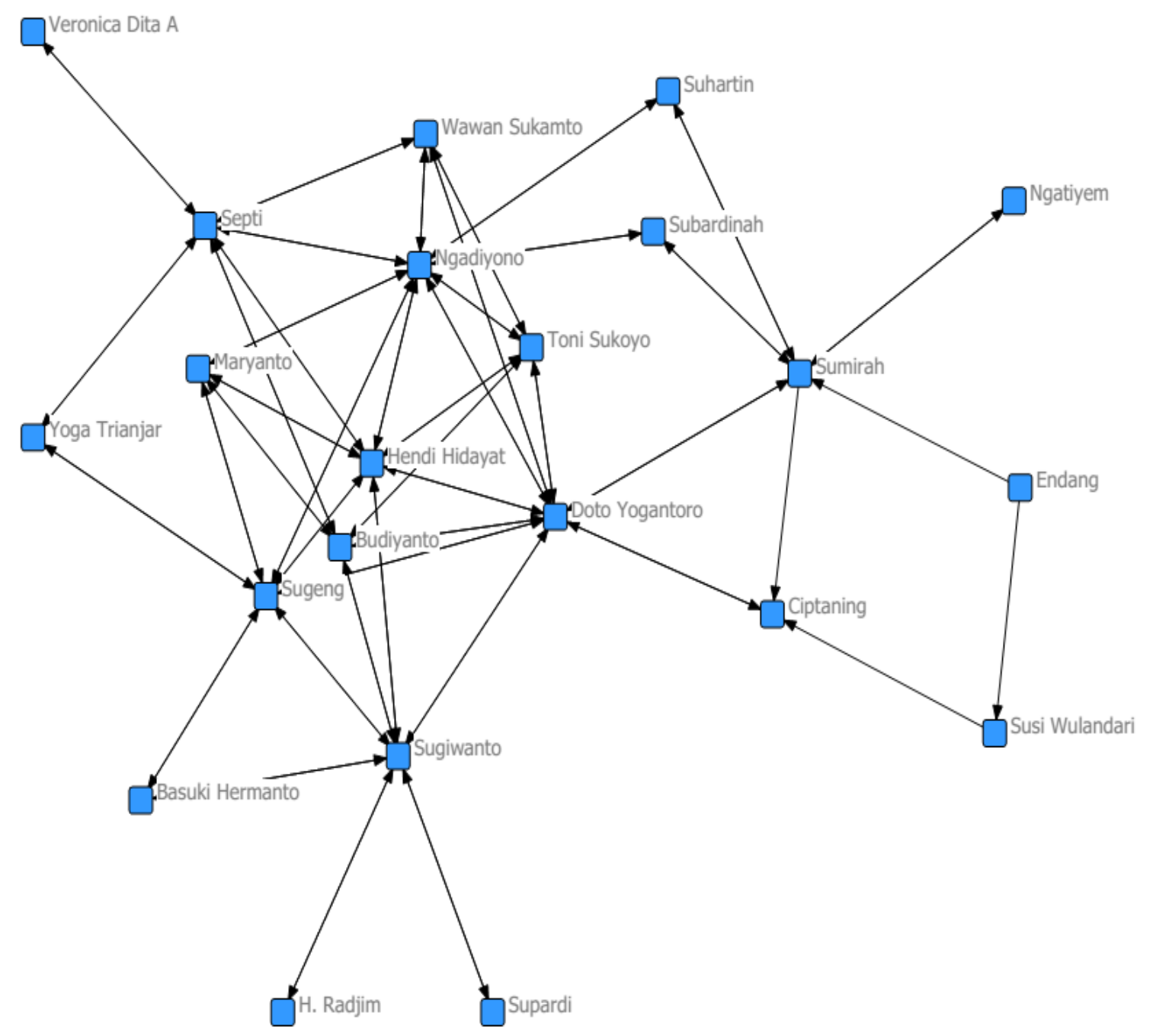

Gambar 1. Sosigram Jaringan Komunikasi 


\section{Diskusi}

Analisa jaringan komunikasi yang dilakukan dalam penelitian ini dilihat pada sentralitas tingkatan, sentralias kedekatan, sentralitas keperantaraan, jumlah klik, kepadatan jaringan dan diameter serta jarak antar aktor.

a. Sentralitas tingkatan

\begin{tabular}{|c|c|c|c|c|c|}
\hline \multirow[t]{2}{*}{ AKTOR } & \multicolumn{3}{|c|}{ DEGREE } & \multicolumn{2}{|c|}{ DEGREE (NORMAL) } \\
\hline & OUT DEGREE & IN DEGREE & $\begin{array}{c}\text { TOTAL } \\
\text { DEGREE }\end{array}$ & $\begin{array}{c}\text { OUT } \\
\text { DEGREE }\end{array}$ & IN DEGREE \\
\hline Doto Yogantoro & 27 & 20 & 47 & 25.714 & 19.048 \\
\hline Budiyanto & 0 & 19 & 19 & 24.762 & 0 \\
\hline Wawan Sukamto & 0 & 13 & 13 & 20 & 1.905 \\
\hline Hendi Hidayat & 0 & 23 & 23 & 18.095 & 0 \\
\hline Maryanto & 9 & 5 & 14 & 14.286 & 20.952 \\
\hline Basuki Hermanto & 0 & 7 & 7 & 13.333 & 0 \\
\hline Ngadiyono & 15 & 22 & 37 & 9.524 & 4.762 \\
\hline Toni Sukoyo & 14 & 0 & 14 & 8.571 & 4.762 \\
\hline Sumirah & 0 & 17 & 17 & 5.714 & 0 \\
\hline Susi Wulandari & 0 & 3 & 3 & 5.714 & 0 \\
\hline Veronica Dita A & 0 & 5 & 5 & 5.714 & 0 \\
\hline Yoga Trianjar & 0 & 6 & 6 & 2.857 & 0 \\
\hline Supardi & 0 & 5 & 5 & 0 & 18.095 \\
\hline Sugiwanto & 26 & 0 & 26 & 0 & 5.714 \\
\hline H. Radjim & 0 & 10 & 10 & 0 & 9.524 \\
\hline Sugeng & 21 & 2 & 23 & 0 & 21.905 \\
\hline Ciptaningtyas & 10 & 5 & 15 & 0 & 6.667 \\
\hline $\begin{array}{l}\text { Endang Tri } \\
\text { Hendrati }\end{array}$ & 6 & 0 & 6 & 0 & 4.762 \\
\hline Ngatiyem & 3 & 0 & 3 & 0 & 12.381 \\
\hline $\begin{array}{l}\text { Septi Dwi } \\
\text { Nugraheni }\end{array}$ & 19 & 0 & 19 & 0 & 16.19 \\
\hline
\end{tabular}




\begin{tabular}{|c|c|c|c|c|c|}
\hline Suhartin & 6 & 0 & 6 & 0 & 2.857 \\
\hline Subardinah & 6 & 0 & 6 & 0 & 4.762 \\
\hline
\end{tabular}

Tabel 2, Sentralitas tingkatan antar aktor

Sentralitas tingkatan menunjukkan Doto (47) adalah seorang opinion leader, disusul oleh Ngadiyono (37), Sugiwanto (26), Sugeng (23) dan Septi (19).

b. Sentralitas kedekatan

\begin{tabular}{|c|c|c|c|c|}
\hline \multirow[t]{2}{*}{ AKTOR } & \multicolumn{2}{|c|}{ CLOSENESS } & \multicolumn{2}{|c|}{ CLOSENESS (NORMAL) } \\
\hline & $\begin{array}{c}\text { OUT } \\
\text { CLOSENESS }\end{array}$ & $\begin{array}{c}\text { IN } \\
\text { CLOSENESS }\end{array}$ & $\begin{array}{c}\text { OUT } \\
\text { CLOSENESS }\end{array}$ & IN CLOSENESS \\
\hline Doto Yogantoro & 78 & 73 & 0.269 & 0.288 \\
\hline Budiyanto & 105 & 72 & 0.2 & 0.292 \\
\hline Wawan Sukamto & 105 & 71 & 0.2 & 0.296 \\
\hline Hendi Hidayat & 105 & 68 & 0.2 & 0.309 \\
\hline Maryanto & 82 & 98 & 0.256 & 0.214 \\
\hline Basuki Hermanto & 105 & 97 & 0.2 & 0.216 \\
\hline Ngadiyono & 82 & 71 & 0.256 & 0.296 \\
\hline Toni Sukoyo & 77 & 105 & 0.273 & 0.2 \\
\hline Sumirah & 105 & 66 & 0.2 & 0.318 \\
\hline Susi Wulandari & 105 & 101 & 0.2 & 0.208 \\
\hline Veronica Dita A & 105 & 101 & 0.2 & 0.208 \\
\hline Yoga Trianjar & 105 & 94 & 0.2 & 0.223 \\
\hline Supardi & 105 & 101 & 0.2 & 0.208 \\
\hline Sugiwanto & 59 & 105 & 0.356 & 0.2 \\
\hline H. Radjim & 105 & 84 & 0.2 & 0.25 \\
\hline Sugeng & 67 & 101 & 0.313 & 0.208 \\
\hline Ciptaningtyas & 82 & 81 & 0.256 & 0.259 \\
\hline Endang Tri Hendrati & 97 & 105 & 0.216 & 0.2 \\
\hline Ngatiyem & 101 & 105 & 0.208 & 0.2 \\
\hline Septi Dwi Nugraheni & 73 & 105 & 0.288 & 0.2 \\
\hline Suhartin & 83 & 105 & 0.253 & 0.2 \\
\hline
\end{tabular}




\section{Subardinah}

83

105

0.253

Tabel 3, Sentralitas kedekatan antaraktor

Dari tabel yang disajikan, Hendi Hidayat adalah aktor yang paling banyak dihubungi anggota-anggota dalam komunitas desa wisata Pentingsari. Sedangkan actor Doto Yogantoro yang paling banyak menghubungi anggota-anggota dalam komunitas desa wisata Pentingsari.

c. Sentralitas keperantaraan

AKTOR

\section{BETWEENNESS}

Doto Yogantoro

31.5

Budiyanto

\section{0}

Wawan Sukamto

0

Hendi Hidayat 0

Maryanto

0.5

Basuki Hermanto

Ngadiyono

21.5

Toni Sukoyo

0

Sumirah

0

Susi Wulandari

0

Veronica Dita A 0

Yoga Trianjar

0

Supardi

0

Sugiwanto 0

H. Radjim 0

Sugeng

Ciptaningtyas 


\begin{tabular}{|c|c|}
\hline Endang Tri Hendrati & 0 \\
\hline Ngatiyem & 0 \\
\hline Septi Dwi Nugraheni & 0 \\
\hline Suhartin & 0 \\
\hline Subardinah & 0 \\
\hline
\end{tabular}

Tabel 4, sentralitas keperantaraan antar aktor

Doto Yogantoro menunjukkan sebagai actor yang paling banyak menjadi perantara antar anggota komunitas desa wisata Pentingsari. Disusul oleh Ngadiyono.

d. Jumlah klik

\begin{tabular}{|l|l|}
\hline & NAMA KLIK (MINIMAL 3 ANGGOTA KLIK) \\
\hline 1 & Doto Yogantoro Hendi Hidayat Ngadiyono Toni Sukoyo \\
\hline 2 & Doto Yogantoro Hendi Hidayat Ngadiyono Sugeng \\
\hline 3 & Doto Yogantoro Hendi Hidayat Sugiwanto Sugeng \\
\hline 4 & Doto Yogantoro Wawan Sukamto Ngadiyono Toni Sukoyo \\
\hline 5 & \\
\hline & \\
\hline
\end{tabular}


Tabel 5, Klik dan anggota klik.

Dari 10 Klik. Aktor Doto yogantoro muncul di 6 klik ini menunjukkan Doto Yogantoro mempunyai kedekatan di hampir semua klik.

e. Kepadatan jaringan, diameter dan jarak antar aktor

\begin{tabular}{|c|c|}
\hline PARAMETER & NILAI \\
\hline Average Degree & 2.045 \\
\hline Density & 0.097 \\
\hline Connectedness & 0.195 \\
\hline Closure & 0.431 \\
\hline Averages Distance & 1.711 \\
\hline Diameter & 4 \\
\hline
\end{tabular}

Tabel 6, Kepadatan jaringan-diameter dan jarak antar actor

Dari table yang disajikan kepadatan jaringan menunjukkan angka sedang 2.045. ini menunjukkan bahwa hubungan antar actor 


\section{Kesimpulan}

Hasil observasi menunjukkan adanya hubungan yang erat antara anggota kelompok. Hal ini sesuai dengan hasil survey yang juga menunjukkan tingginya derajad keterhubungan dan derajad integrasi individu. Peranan Opinion Leader terlihat jelas dalam observasi yang digambarkan dengan tingginya aktivitas mereka. Yang terlihat dalam rapinya pengelolaan, kooperatifnya penduduk desa, dan apiknya potensi alam dan budaya menjadikan Pentingsari semakin solid sebagai desa wisata. Desa ini tlah mendapatkan sejumlah penghargaan, antara lain Juara I lomba Desa Wisata se -Daerah Istimewa Yogyakarta (2009), Appreciation For Best Practise On Tourism Ethics at Local Level World Committee On Tourism Ethics - UNWTO

(Juni 2011), dan juara III kategori ekonomi pada Indonesia Sustainable Tourism Award 2017

\section{Daftar Pustaka.}

Bungin, Burhan. 2007. Penelitian Kualitatif Komunikasi, Ekonomi, Kebijakan Publik, Dan Ilmu Sosial Lainnya. Jakarta: Kencana.

Rogers, Everett, M 1995. Communication Network: Toward a New Paradigm for Research. London; Collier Publisher.

Eriyanto. 2014. Analisis Jaringan Komunikasi Strategi Baru Dalam Penelitian Ilmu Komunikasi Dan Ilmu Sosial Lainnya. Jakarta. Prenada Media Group.

Rogers, Everett M. 1969. Modernization Among Peasant The Impact Of Communication. New York : Holt, Rinehart and Winston,Inc 